\title{
ARTE EN LA MESA: SALEROS Y ESPECIEROS ARAGONESES DE ÉPOCA MODERNA
}

\author{
Marc Millan Rabasa \\ Investigador predoctoral en la Universidad de Zaragoza.marcmillanrabasa@unizar.es
}

\begin{abstract}
In this paper we focus on salt and spices cellars, a kind of object we will study from a gastronomic, artistic and socioeconomic perspective. To achieve this purpose, we will make a catalogue with pieces from art from museums, private collections, cathedrals and parishes, so we'll get to know the important role spices had in the aragonese tables and kitchens in the 16th, 17th and early 18th centuries. In addition, a large amount of notarial documentation, graphic and pictorial representations and literary testimonies will be presented to illustrate certain artworks that have disappeared.
\end{abstract}

Keywords: silver smithery, gold smithery, feast, Aragon, Zaragoza, pottery, spices, salt, eating, gastronomy.

Resumen: En esta comunicación centramos nuestra atención en los saleros o especieros, una tipología de objetos que abordaremos desde una perspectiva tanto gastronómica como artística y socioeconómica. Recogiendo obras conservadas en museos, colecciones particulares, catedrales y parroquias vamos a conocer el importante papel que las especias tenían en las mesas aragonesas de los siglos XVI, XVII e inicios del XVIII. Con este objetivo aportamos numerosa documentación procedente de los archivos notariales, con especial énfasis en la aparición de estos recipientes en inventarios y tasaciones. Así mismo, también nos serviremos de su representación pictórica y gráfica y algunos ejemplos literarios, todo ello con el objetivo de ilustrar aquellos ejemplares que no se han conservado.

Palabras clave: platería, orfebrería, banquete, Aragón, Zaragoza, cerámica, especias, sal, alimentación, gastronomía.

Citar como: Millan Rabasa, M. (2022). "Arte en la mesa: saleros y especieros aragoneses de Época Moderna". En: Actas del III Congreso Internacional sobre Patrimonio Alimentario y Museos. 25-26 noviembre, 2021, Valencia, España. pp. 39-59. https://doi.org/10.4995/EGEM2021.2021.13302 
En 1643 la vizcondesa de Torresecas, Magdalena Cortés y Sangüesa, recibió en su casa al sacerdote Francisco Lafiguera. Este había invitado a comer al conde de Pliego y se veía incapacitado para desplegar el ajuar y la vajilla necesarios para agasajar a tan importante comensal. Entonces, el clérigo pidió a la vizcondesa que le prestara todo lo necesario para dar un toque de distinción a su mesa. Ella accedió entregándole platos, fuentes, cubertería, copas, manteles, servilletas, toaIlas, un salero e incluso joyas y algún reloj que, si bien no estaban directamente relacionados con los usos gastronómicos, podían impresionar al invitado. Desgraciadamente, la buena voluntad de la noble no se vio correspondida, pues el sacerdote nunca le llegaría a devolver tales objetos (Postigo, 2015, pp. 157-166).

Esta historia, rescatada de entre las causas criminales del Archivo Diocesano de Zaragoza por Juan Postigo para su libro La vida fragmentada, muestra la importancia de los banquetes como herramienta de representación social. Como hemos visto, el salero formaba parte de los objetos entregados por la vizcondesa de Torresecas para que el presbítero pudiese celebrar una comida digna de un conde, una persona de gran relevancia social y política, con el presunto objetivo de fortalecer una relación personal con la que obtendría ciertos beneficios. En las próximas páginas vamos a centrarnos tanto en estos recipientes como en los ingredientes que solían guardar y exhibir, la sal y las especias.

\section{El papel de las especias en las cocinas aragonesas de Época Moderna}

La sal y, especialmente, las especias eran muy valoradas por su sabor, su aroma y sus propiedades terapéuticas desde época romana. Encontramos estos sazonadores en libros de medicina (Eberenz, 2018, p. 1078) y en numerosos recetarios para enriquecer un sin fin de platos, tanto cárnicos como vegetales, así como bebidas analcohólicas y vinos (Pérez, 1997). Dejando atrás las hipótesis que sugieren que su principal uso se limitaba a la conservación de los alimentos, actualmente sabemos que los comensales que nos precedieron deseaban que sus platos fuesen sorprendentes y fragantes, que exudaran lujo y exotismo gracias a los productos traídos desde los confines de la tierra conocida (Riera, 2004).

La sal era el más común de estos condimentos y, en consecuencia, el más fácil y económico de adquirir. El principal factor que permitía esta abundancia en el mercado era su producción en varios enclaves del propio reino de Aragón. Su extracción a nivel industrial era controlada por la nobleza o asignada a monasterios, órdenes religiosas y compañías comerciales particulares, como en el caso de las salinas de Ojos Negros (Martín, 2009).

Gracias a los inventarios de boticarios y mercaderes podemos conocer cuáles eran las especias más comunes en el comercio aragonés. El azafrán es un caso particular al ser la única producida en territorio hispánico (Garrido/Hidalgo/Ramírez, 2004). Rescatamos en este lugar un contrato para su cultivo firmado entre Martín de Peralta, canónigo de la Seo de Zaragoza, y el labrador Gil de Xubierre en 1605, del que el religioso salía muy beneficiado económicamente. ${ }^{1}$ Sin embargo, este hecho no lo convertía en un producto más económico. Tal era su valor que, como si de un metal precioso se tratase, se adulteraba para aumentar las ganancias. Para controlar dicha falsificación el concejo de Zaragoza contaba con la figura del veedor de azafrán. Se trata de un cargo totalmente efectivo pues Juan Domingo Navarro, quien lo ocupaba en 1606, incautó

\footnotetext{
Archivo Histórico de Protocolos Notariales de Zaragoza [AHPNZ], Nicolas Cascarosa, 1602-1605, ff. 565 r.-569 v. (1-VI1605, Monegrillo).
} 
un cargamento adulterado con una tercera parte de almidón, miel y flor de cardo (San Vicente, 1988, pp. 69-70, doc. 378).

Igual o más popular que el azafrán era la pimienta, de importación en cualquiera de sus variedades, que no podía faltar en la mesa de los más adinerados. Como en el caso anterior, el concejo de Zaragoza atendía a su correcta comercialización. Por ejemplo, en 1639 la corporación municipal procedió a la regularización de su precio. Fue fijado en "siete reales por cada libra", pues los mercaderes adquirían los granos a un precio muy bajo y luego especulaban aumentándolo desmesuradamente, considerando que hacían "exceso y daño grande [...] en esta ciudad". Cualquiera que la vendiese a un precio mayor se enfrentaba a una pena de 60 sueldos de multa y se le requisaría toda la pimienta que poseyese (San Vicente, 1988, p. 188, doc. 451). En otras memorias e inventarios también hemos encontrado canela, clavos de girofle o "de Romanía", nuez moscada, diversos tipos de jengibre, comino, mostaza, cilantro y algunas hierbas aromáticas. $^{2}$ Todos estos ingredientes se podían comercializar en grano o molidos (San Vicente, 1988, pp. 104-113, doc. 77; pp. 329-340, doc. 173) y su mera consecución ponía de relieve la capacidad económica del anfitrión que las ofreciese en el banquete.

En los documentos que hemos referido hasta el momento encontramos las especias en las tiendas de los boticarios y las cocinas de los ciudadanos almacenadas en orzas, cajitas, cestas u otros recipientes cerámicos situados cerca de la fuente de calor (Abad, 2005, p. 169). Yelgo de Bázquez escribe en 1614 que los condimentos se deben guardar en bolsas (Yelgo, 1614, p. 155). No será ninguno de estos objetos cómodos a la hora de trabajar, pero lejos de la opulencia de las mesas nobles, los que centren nuestra atención. Los saleros y especieros que analizaremos a continuación no almacenaban los condimentos, sino que los hacían visibles y accesibles al comensal una vez el banquete se había iniciado.

\section{Una doble expresión del lujo: especias y especieros en las mesas aragonesas}

Los objetos que protagonizan esta comunicación se encuentran en la intersección de dos factores que condicionan su existencia. Por una parte, habían de contener y exhibir productos alimenticios que, por lo general, solo podían permitirse las familias acaudaladas. Además, ocupaban su espacio sobre la mesa en actos de gran importancia social. Esto motivó que las tipologías de saleros y especieros se desarrollaran acordes tanto a los usos gastronómicos como a los determinantes sociales y económicos de su época.

En el filo del año 1500 no existe todavía un tipo fijo de salero en el ámbito hispánico, cosa que favorece el reaprovechamiento de algunos objetos. Estos intercambios entre el ámbito civil y el religioso eran muy comunes, como ejemplifican las navetas "para incienso o saleros" que se hallan en el inventario de bienes de Isabel la Católica (Andrés/Naya, 2012, p. 383). También encontramos este fenómeno documentado en Aragón en las décadas cercanas al cambio de siglo, en este caso "un salero de argent dorado do[nde e]sta el Corpus Christi con su velo encima" en la iglesia de San Felipe de Zaragoza, "un salero blanco de plata con titulo de IHS" entre los bienes de Antón Lobera (Gómez, 2017, p. 161, doc. 102 bis; p. 199, doc. 133) e incluso "un salero

\footnotetext{
2 Para esta lista de especias también se han consultado los documentos siguientes. AHPNZ, Pablo de Gurrea, 1530, ff. 374 r. y ss. [s.f.] (12-V-1530, Zaragoza); AHPNZ, Pablo de Gurrea, 1537, ff. 757 r.-772 v. (9-V-1537, Zaragoza); Francisco Moles, 1606, ff. 48 v.-50 r. (6-I-1606, Zaragoza); Archivo Histórico Provincial de Teruel [AHPT], Francisco Malo, 1613, ff. 126 r.-128 r. (25-X-1613, Teruel). Agradecemos a Juan Carlos Calvo Asensio que nos haya facilitado los documentos de origen turolense que nos han servido para confeccionar esta comunicación.
} 
grande de plata a modo de sepoltura" de Tomás Fort, arcediano de la Seo de Huesca (Cardesa, 1993, p. 313, doc. 35). En cualquier caso, parece tratarse de recipientes que podían adaptarse a las circunstancias de sus propietarios.

Este fenómeno tuvo como consecuencia que diversos ejemplares civiles de gran opulencia entrasen durante siglos, a modo de donación, en tesoros catedralicios y parroquiales. El caso mejor estudiado es la preciosa naveta gótica con caracol nautilus de la catedral del Salvador donada por el caballero Juan de Torrellas en 1481, que no podemos obviar pese a ser temprana respecto a la cronología que aquí tratamos (Andrés/Naya, 2012). Encontramos otra pieza similar en la parroquia de san Pablo de la capital aragonesa (Figura 1). Cuenta en la parte inferior de su pie con el punzón de José Godó y de Zaragoza, con una datación del primer tercio del siglo XVIII (Esteban, 1981, t. I, p. 123; t. II, p. 184).

Este incensario perteneció, en origen, al ámbito civil, como marcan el escudo a modo de tapa y la iconografía marina de su pie formado por la unión de una concha, un delfín y un angelote que sostiene el caracol. Los temas acuáticos eran muy frecuentes en las piezas de vajilla, recipientes y otros elementos de ajuar de mesa. Además, los saleros permiten explotar especialmente estos motivos por el sabor salado del agua del océano. No se trata de una relación iconográfica exclusiva del ámbito hispánico como demuestran el célebre salero que Benvenuto Cellini labró para Francisco I de Francia con Neptuno y la personificación de la tierra, expuesto en el Kunsthistorisches de Viena, y el salero de ónice con sirena de oro del tesoro del Delfín, obra maestra de la orfebrería francesa en el Museo del Prado.

Sin embargo, podemos apuntar otra relación simbólica con el mundo náutico que encaja con las motivaciones sociales de la celebración de un banquete y con la utilización de las especias. Como hemos indicado, la mayoría se importaban desde territorios lejanos, especialmente desde Asia. En los inventarios se enumeran numerosos navíos decorativos, sin función aparente, pero guardados junto a vajillas, copas y saleros. También hemos documentado que Tomás Fort, canónigo de la Seo de Huesca, poseía "dos otros medios saleros a modo de barca" (Cardesa, 1993, p. 313, doc. 35). Por ello pensamos que estaban destinados a evocar sobre la mesa los largos viajes que los ingredientes, con énfasis en las especias, habían realizado hasta la boca de los comensales. La presencia de estas naves se documenta en diversas crónicas desde la Baja Edad Media como elemento de fastuosidad (Andrés/Naya, 2012, pp. 377-378) y la presencia de nautilus sacados de las aguas y manufacturados en Europa Central apunta en la misma dirección (Cruz, 1997, pp. 186-193).

Encontramos otros recipientes de origen aragonés con llamativas caracolas en museos y el mercado artístico, aunque sus formas encajan más con una copa que con un salero. ${ }^{3}$ En cualquier caso, muestran el interés que causó esta tipología de manera ininterrumpida hasta finales del siglo XVIII. En el Museo Nacional de Artes Decorativas de Madrid se conserva una copa en la que el caracol va engarzado en una pieza de origen germánico (Figura 2). Sin embargo, el pie presenta los punzones de Barbastro y Francisco Subías (Alonso, 2015, p. 182; Castillón, 2002, p. 73) que nos permiten datarla en la primera mitad del siglo XVII. Composición muy similar

\footnotetext{
3 También se han localizado piezas a nivel documental. La primera de ellas en el testamento del canónigo Francisco de Herbas. Se trata de "un baso de nacre o de concha guarnecido de plata sobredorada con pie alto y su basera". En AHPNZ, Francisco Martín Antich Bagés, 1605, ff. 1746 r.-1761 v. (23-IX-1605, Zaragoza). En segundo lugar, entre los bienes que Juan de Funes Villalpando dio a su hijo Francisco en 1640 había "un caracol de Indias con una cabeza y garra de agila de plata dorada tassado en cinquienta libras jaquesas" (Latorre, 1984, doc. 2995).
} 


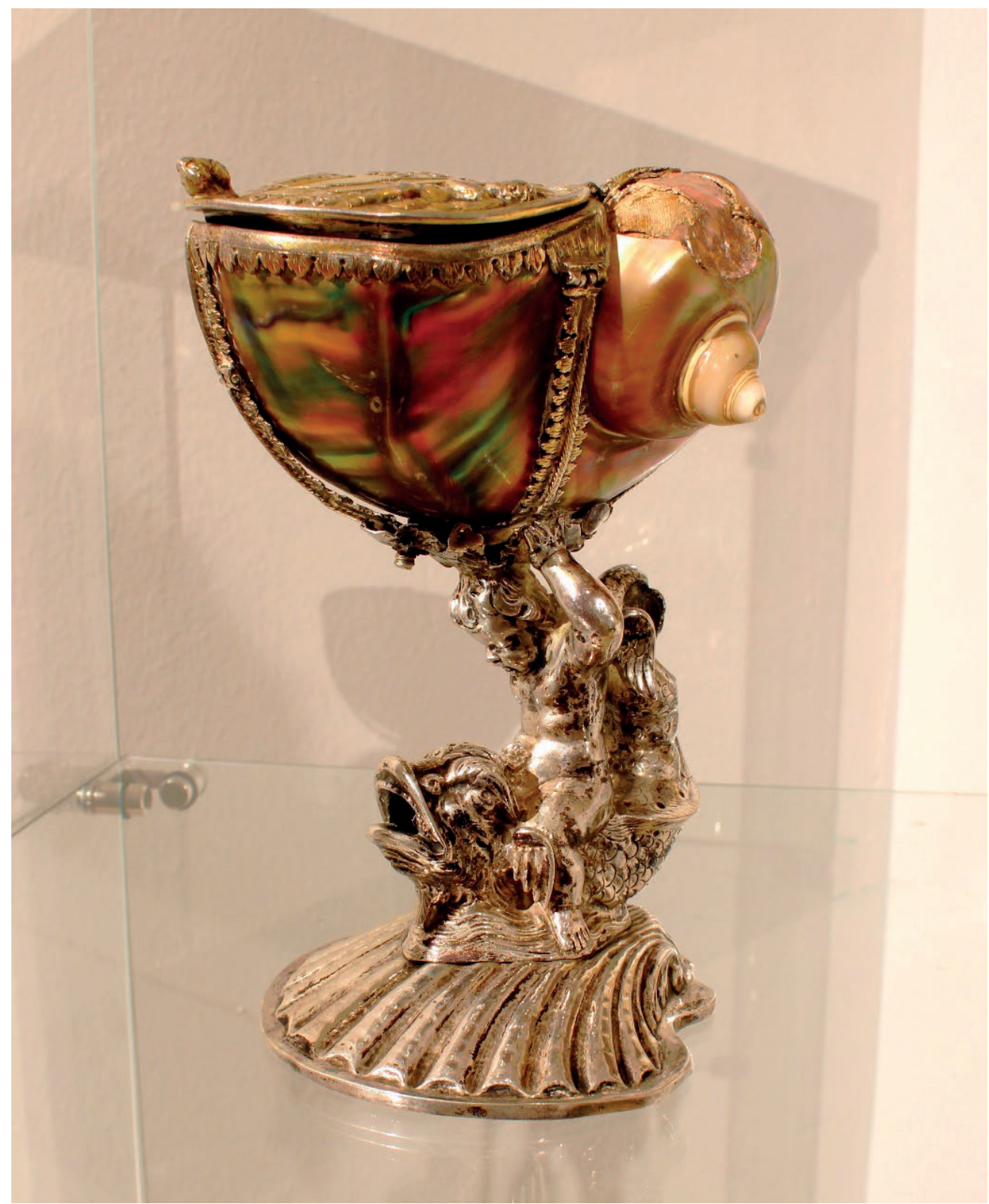

Figura 1. Salero o incensario de la parroquia de san Pablo de Zaragoza. José Godó, primer tercio del siglo XVIII. Fuente: elaboración propia.

presenta la copa expuesta en 1979 en la sala de arte Daedalus. En este caso la pieza del caracol dataría del siglo XVII, pero el nudo y el pie presentan los punzones de Zaragoza y del platero Domingo Estrada que corresponden a la segunda mitad del siglo XVIII (Maldonado/Montuenga, 1979, cat. 21). También se le puede imputar otra copa que apareció en subasta en Christie's, con 


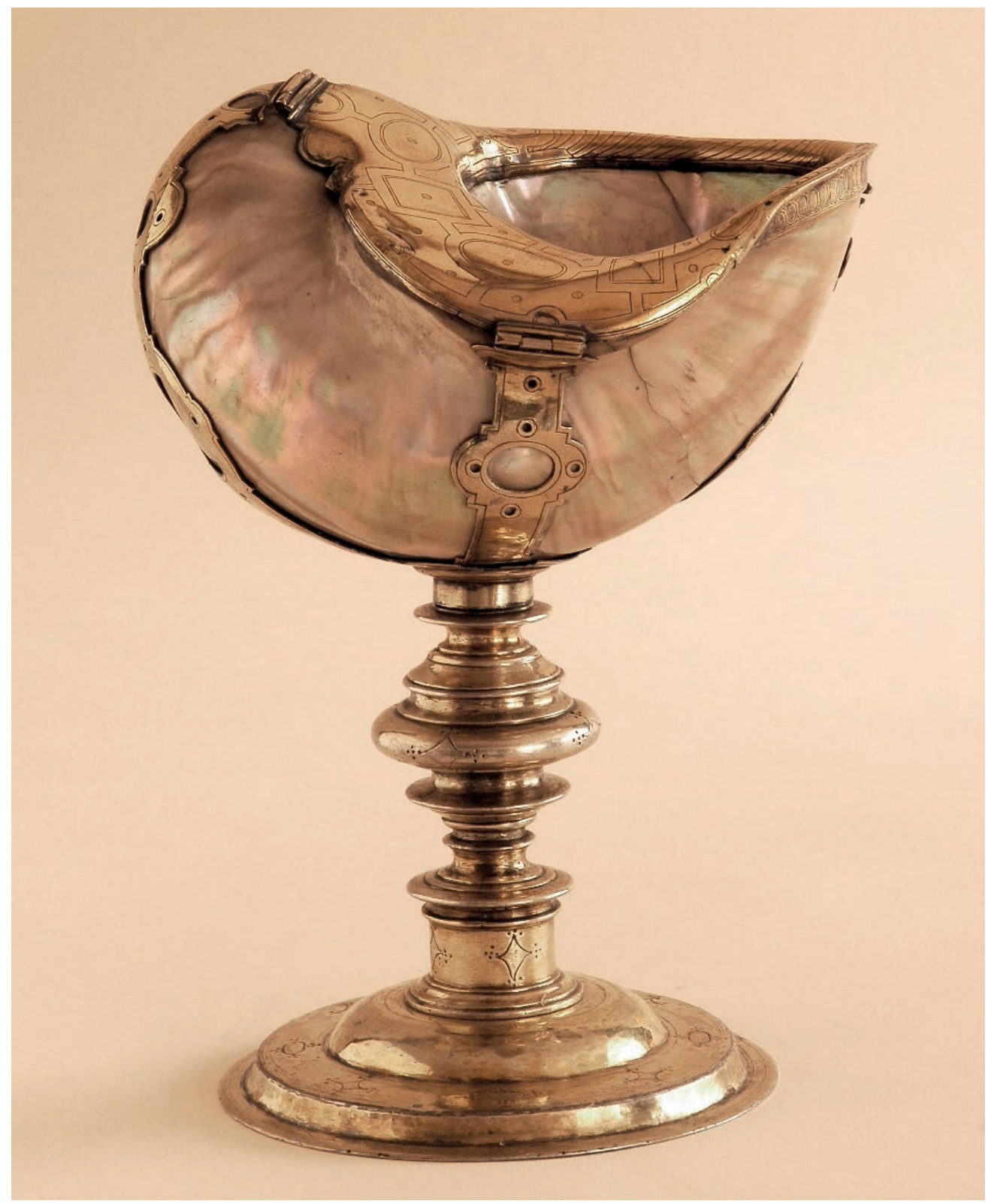

Figura 2. Copa. Taller alemán y Francisco Subías, siglo XVI e inicios del XVII. Fuente: Museo Nacional de Artes Decorativas.

una datación más cercana al año 1800 (Cruz, 2014), que cerraría cronológicamente esta serie de obras aragonesas donde el nautilus es el protagonista.

Un último ejemplo de estos saleros extraordinarios conservados en el ámbito eclesiástico es la naveta de la catedral de Albarracín (Figura 3), manufactura de taller milanés realizada en el 


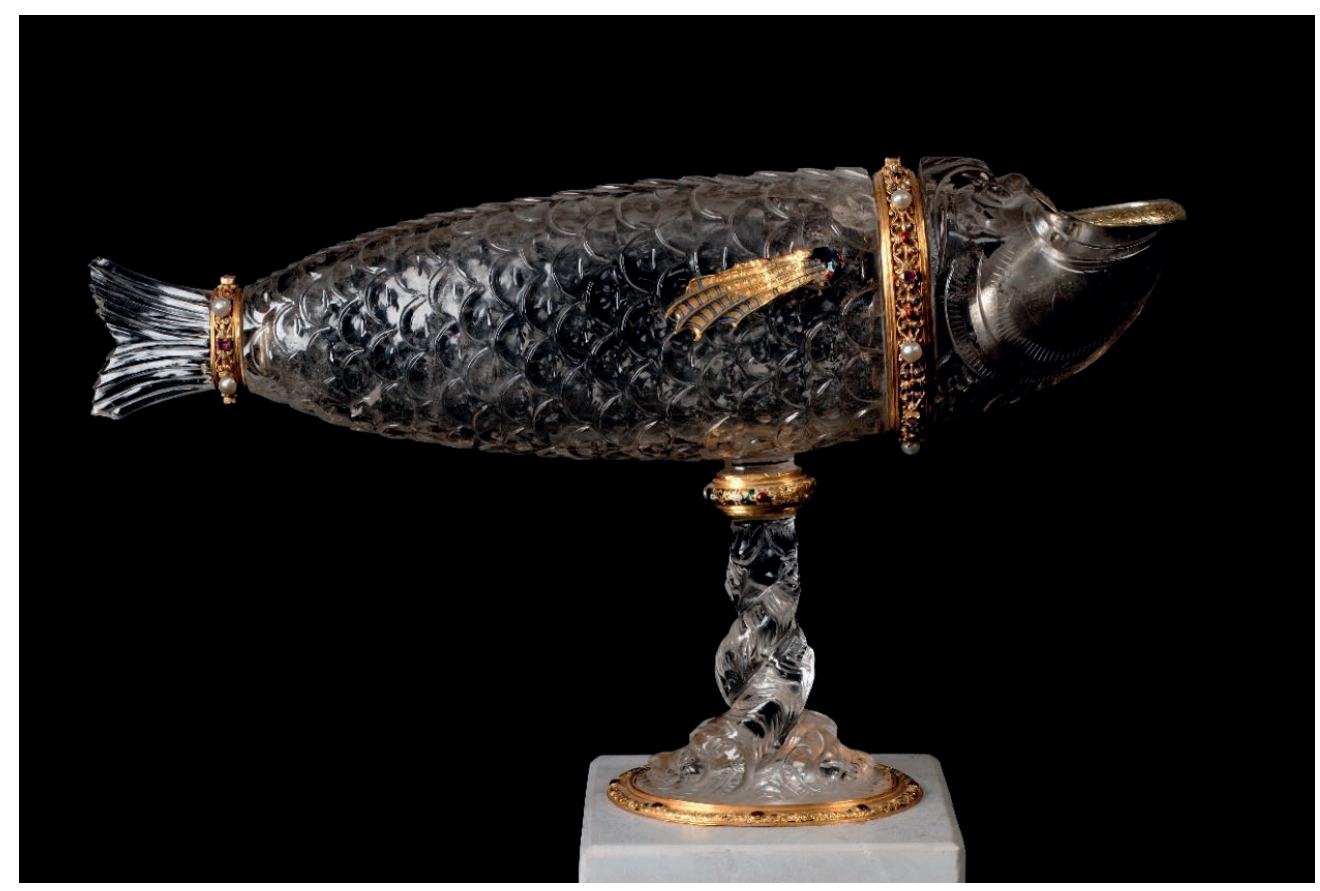

Figura 3. Salero o naveta de cristal de roca. Taller milanés, siglo XVI.

Fuente: Fundación Santa María de Albarracín.

último cuarto del siglo XVI. Pese a la divergencia material, coincide con las piezas anteriores por la variedad y riqueza de los elementos que la conforman. En este caso el protagonista es el cristal de roca tallado en forma de pez. En su cuerpo se engarzaron perlas, piedras de colores y piezas de oro y plata torneadas, moldeadas, grabadas y cinceladas. Pese a la cronología indicada, no tenemos noticias de la pieza hasta 1743, cuando aparece por primera vez en los inventarios catedralicios indicando que fue donada por el deán Agustín Roa, presumiblemente a inicios del siglo XVIII. Originalmente, el religioso usaría el recipiente como salero, pero al llegar a la catedral fue convertido en incensario o salero bautismal, cosa que como hemos indicado era del todo usual (Cruz, 1997, p. 164; Esteras, 1975, pp. 108-109; Esteras, 1980, cat. 194; Arce, 2015).

Todos los especieros que hemos visto hasta ahora pertenecen a la variante más lujosa, que en ningún caso era la más popular. Los inventarios que hemos recogido para esta investigación, especialmente los del primer tercio del siglo XVI, muestran una gran variedad material que abarataría el producto. Esta gama más económica iría dirigida a aquellos comerciantes, altos artesanos u otros ciudadanos que pudiesen adquirir especias con mayor o menor frecuencia o bien serían usados como contenedores de sal, ingrediente más común en las cocinas. Hemos 
hallado saleros y pimenteras de plomo, ${ }^{4}$ estaño, ${ }^{5}$ bronce, ${ }^{6}$ madera, ${ }^{7}$ cristal blanco o de colores, ${ }^{8}$ piedra $^{9}$ y cerámicos. ${ }^{10}$

Esta gran diversidad nos indica que eran producidos por numerosos gremios como herreros, vidrieros o ceramistas; por lo que asumimos una demanda relativamente elevada. Contamos con un documento que atestigua la fabricación de saleros de tierra en Morata de Jalón. Se trata de un contrato firmado en 1576 entre un grupo de escudilleros de esta localidad y el mercader zaragozano Gaspar Serra para la producción y el suministro de diversas tipologías de vajilla, entre las cuales unas "salericas, a razon de tres sueldos y quatro dineros" (San Vicente, 1991, pp. 266-269, doc. 217). Para conocer como son formalmente estos elementos de mesa tenemos que acudir a la producción alfarera turolense. Se conservan varios ejemplares en el Museo Nacional de Artes Decorativas de Madrid, en el antiguo Museo de Cerámica de Barcelona (Abad, 2005, p. 170) y en el Museo Diocesano de Teruel (Figura 4). En todos los casos se trata de piezas de formas muy sencillas con uno o dos espacios para colocar la sal y alguna otra especia y cuyos motivos decorativos se integran en las series típicas de la producción local. En la pintura La Cena de San Benito de fray Juan Andrés Rizi, en las colecciones del Museo del Prado, vemos representado un sencillo salero que refrenda este uso (Figura 5).

Hasta este momento hemos visto los objetos más caros y extravagantes, creados con los materiales más exclusivos, y otros más humildes que formaban parte de la cotidianeidad de un grupo más amplio de aragoneses. Sin embargo, los saleros y especieros que encontramos con más frecuencia en la documentación son aquellos que, careciendo de la espectacularidad de los primeros, seguían siendo un objeto de valor por el material con el que estaban hechos: la plata. Los inventarios de época aportan pocos datos respecto a su forma, aunque imaginamos que se equiparaban a los saleros cerámicos y tenían entre uno y cuatro espacios para las especias. ${ }^{11}$ En algunas ocasiones sí se indica su apariencia, siendo los cilíndricos y los de planta cuadrada los más comunes. ${ }^{12}$ En la colección del Instituto Valencia de don Juan se conserva un ejemplar punzonado en Zaragoza, datado en el primer tercio del siglo XVII (Montalvo, 2009, fig. 10) y con una sencilla decoración de volutas y óvalos o espejos (Figura 6).

\footnotetext{
4 Inventario de bienes de María San Martín. En AHPNZ, Jerónimo Sora, 1538, ff. 603 r.-610 r. (7-X-1538, Zaragoza).

5 Inventario de Catalina Fabra y Ana de Alfaro. En AHPNZ, Jerónimo Sora, 1532, ff. 24 r.-27 v. (5-III-1532, Juslibol). Inventario de bienes de la casa de Catalina Cresti, viuda del pelaire Joan Polo. En AHPNZ, Juan Arruego, 1530, ff. 404 r.-410 v. (26-IV-1530, Zaragoza). Agradecemos a Pablo Cercós Maícas que nos haya facilitado la referencia de este último documento.

6 Tasación de los bienes que Juan Pérez, ciudadano de Teruel. En AHPT, Miguel Jerónimo Escobedo, 1651, ff. 6 v.-21 v. (3-I-1651, Teruel).

7 Inventario de Inés de Villaraça. En AHPNZ, Pablo de Gurrea, 1534, ff. 473 v.-479 r. (5-X-1534, Zaragoza).

8 Inventario de los hijos de Juan de Navas, mercader. En AHPNZ, Jerónimo Sora, 1534, ff. 108 r.-114 v. (27-III-1534, Zaragoza). Inventario de bienes de Juan de Paraíso, labrador. En AHPNZ, Jerónimo Sora, 1540, ff. 65 v.-72 r. (2-III-1540, Zaragoza). Inventario de bienes de Pedro de Çaffra, bonetero. En AHPNZ, Pablo de Gurrea, 1540, ff. 228 v.-231 r. (29-V-1540, Zaragoza).

9 Inventario de bienes de Juan de Usón menor, labrador. En AHPNZ, Jerónimo Sora, 1550, ff. 106 v.-112 v. (1-V-1550, Peñaflor).

10 Inventario de los hijos de Juan de Navas, mercader. En AHPNZ, Jerónimo Sora, 1534, ff. 108 r.-114 v. (27-III-1534, Zaragoza). Inventario de bienes de Miguel Clemente. En AHPNZ, Jerónimo Sora, 1549, ff. 184 v.-193 r. (23-VIII-1549, Zaragoza).

${ }^{11}$ Sirva a modo de ejemplo el "salero hecho en quatro piecas" del inventario del infanzón zaragozano Jaime Salvador. En AHPNZ, Jerónimo Sora, 1544, ff. 227 v.-233 v. (27-VIII-1544, Zaragoza).

${ }^{12}$ En el sorteo realizado para el convento de la Santa Cruz de Jaca se subastaron dos saleros "dorado[s] y quadrado[s] de tres pieças" con los números 21 y 33 y otro "de tres pieças dorado redondo" con el 41. Como en la mayoría de ocasiones, no se indica si eran de torre o más sencillos. En AHPNZ, Lupercio Andrés, 1607, ff. 636 r.-652 v. (6-X-1607, Zaragoza).
} 


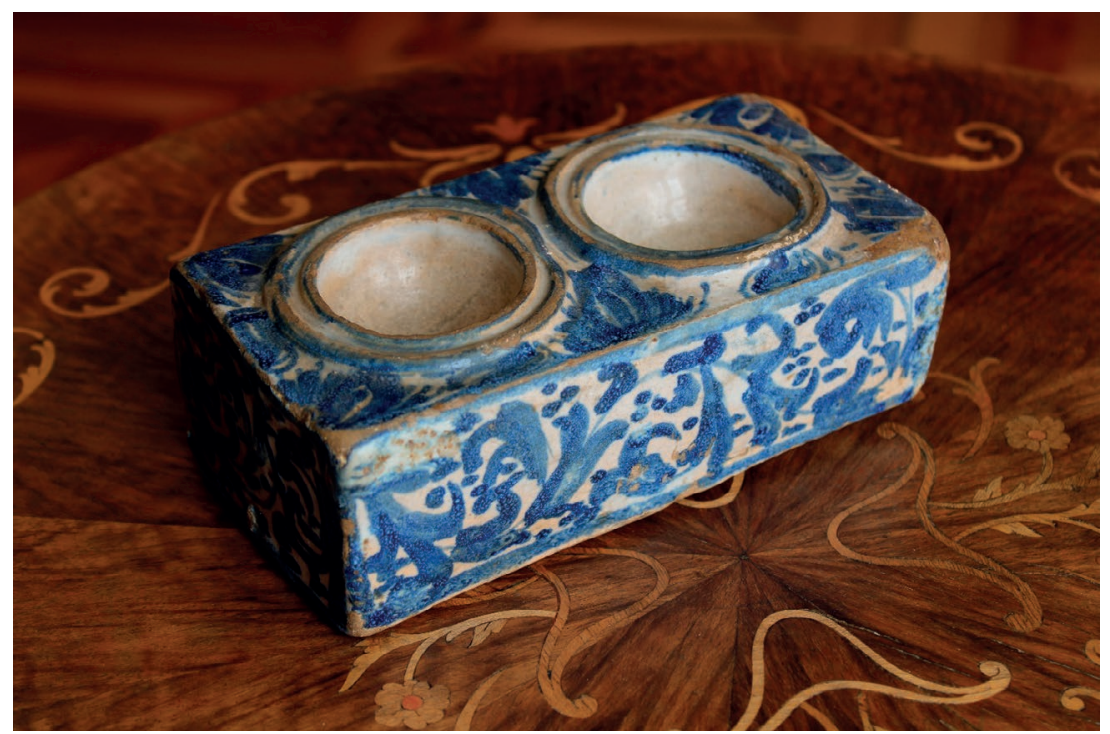

Figura 4. Especiero cerámico del Museo Diocesano de Teruel. Taller turolense, segunda mitad del siglo XVII o inicios del XVIII.

Fuente: Juan Carlos Calvo Asensio.

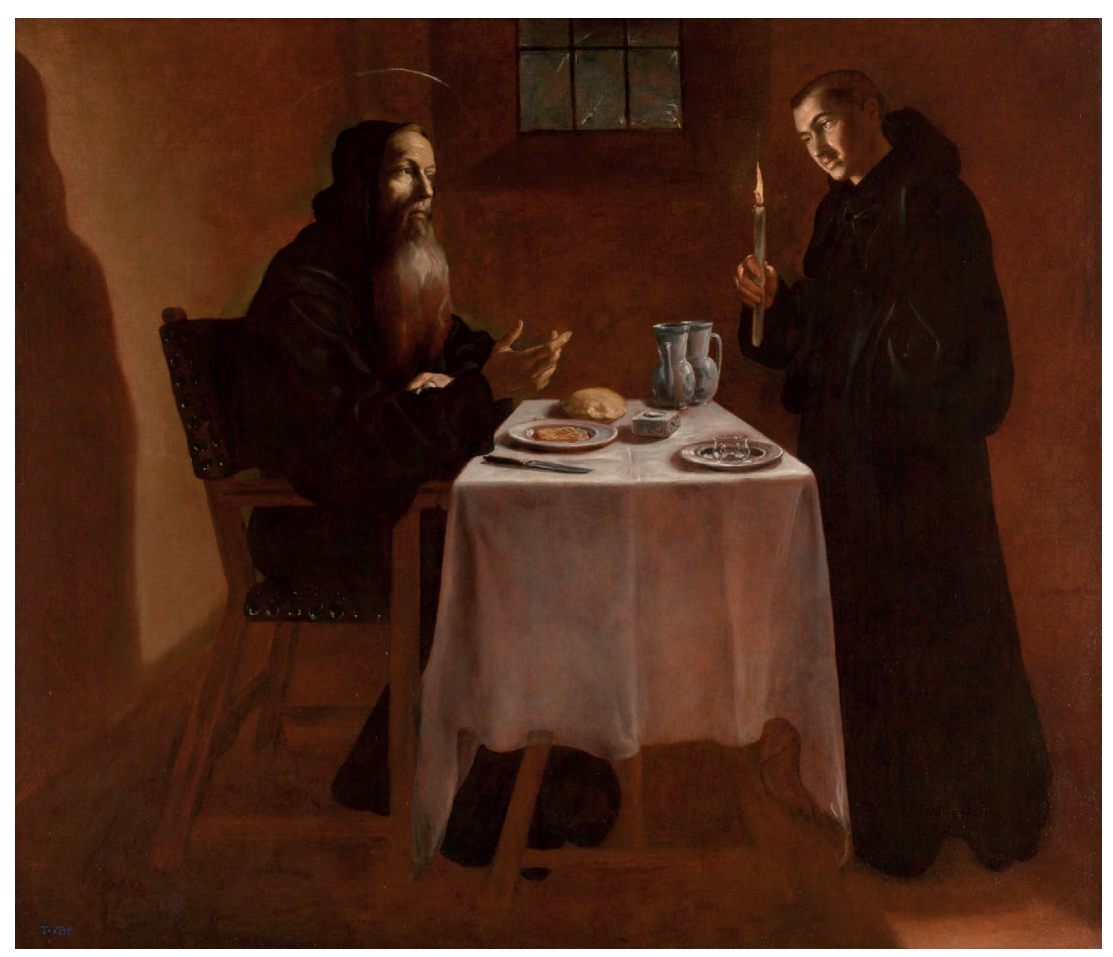

Figura 5. La cena de San Benito [detalle]. Fray Juan Andrés Rizi, siglo XVII.

Fuente: Museo Nacional del Prado. 


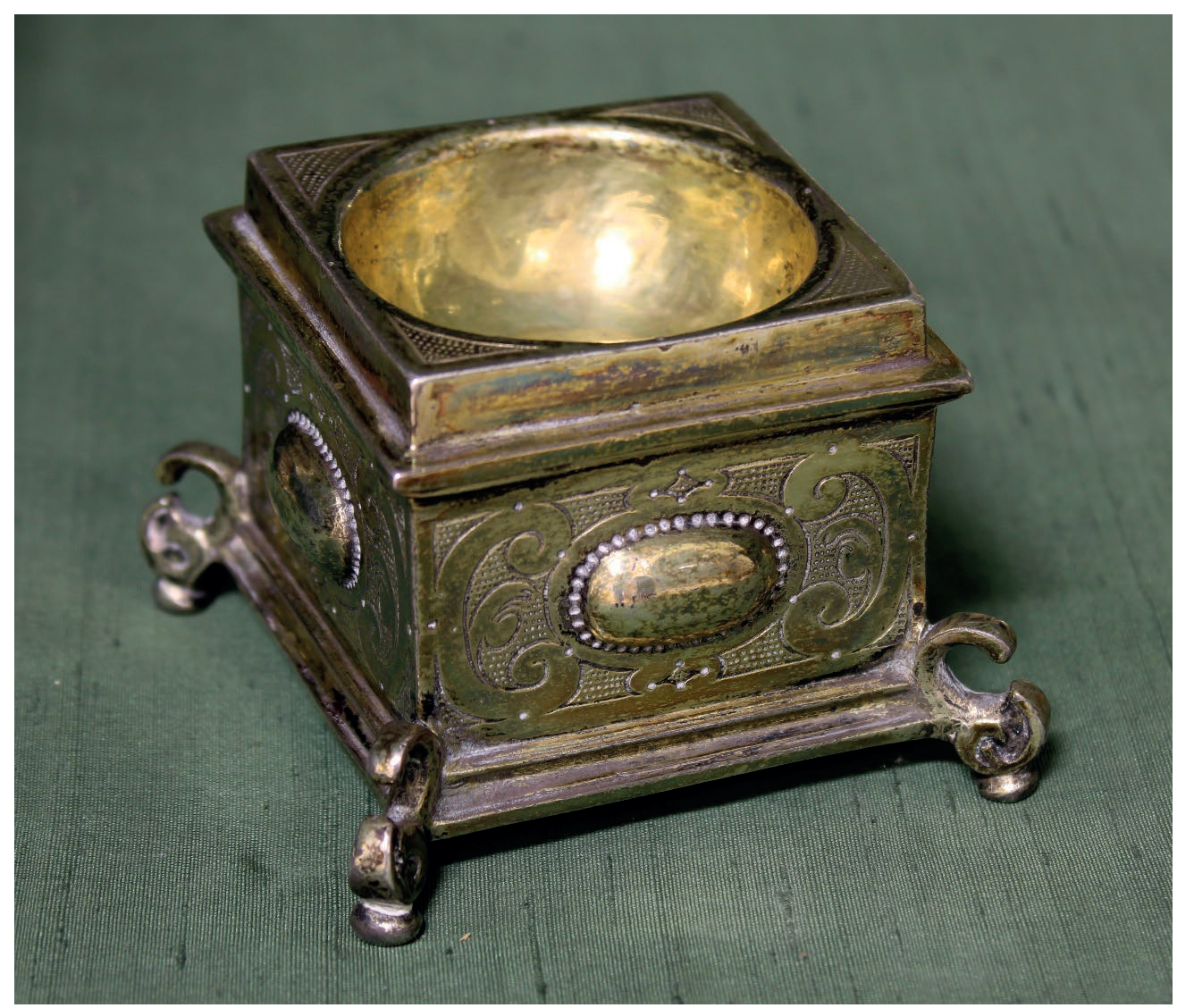

Figura 6. Salero del Instituto Valencia de Don Juan. Taller zaragozano, primer tercio del siglo XVII. Fuente: el autor.

Se acentúan todavía más las semejanzas con los modelos cerámicos en otro salero que conserva el Museo Arqueológico Nacional, con la misma marca de ciudad y cronología ligeramente anterior, alrededor del año 1600 (Figura. 7). Se ha indicado que su forma triangular con tres pocillos es excepcional en el ámbito de la platería, con la única referencia de otro ejemplar germánico en el Victoria \& Albert Museum (Mañueco, 2002). Sin embargo, su estructura es idéntica a la producida en los talleres de Talavera de la Reina, entre otros centros cerámicos, con ejemplos conservados en el Museo Nacional de Artes Decorativas (Figura 8). En todo caso, su hechura en plata y la iconografía de raíz clásica nos llevan a un mercado más restringido que el de los productos de alfarería.

Hasta ahora hemos visto que la sal y las especias debían descansar encima de la superficie del objeto, pero en el tercer cuarto del siglo XVI se desarrollará otra tipología llamada salero de torrecilla o mendocino. El primer término hace referencia a la forma de torre resultado de la superposición de varios cuerpos, culminando con uno más pequeño donde se sitúa un receptáculo para dosificar la sal o la pimienta cómodamente. En cambio, el segundo parece tener que ver con una antigua superstición de la familia noble de los Mendoza, que creía que derramar 


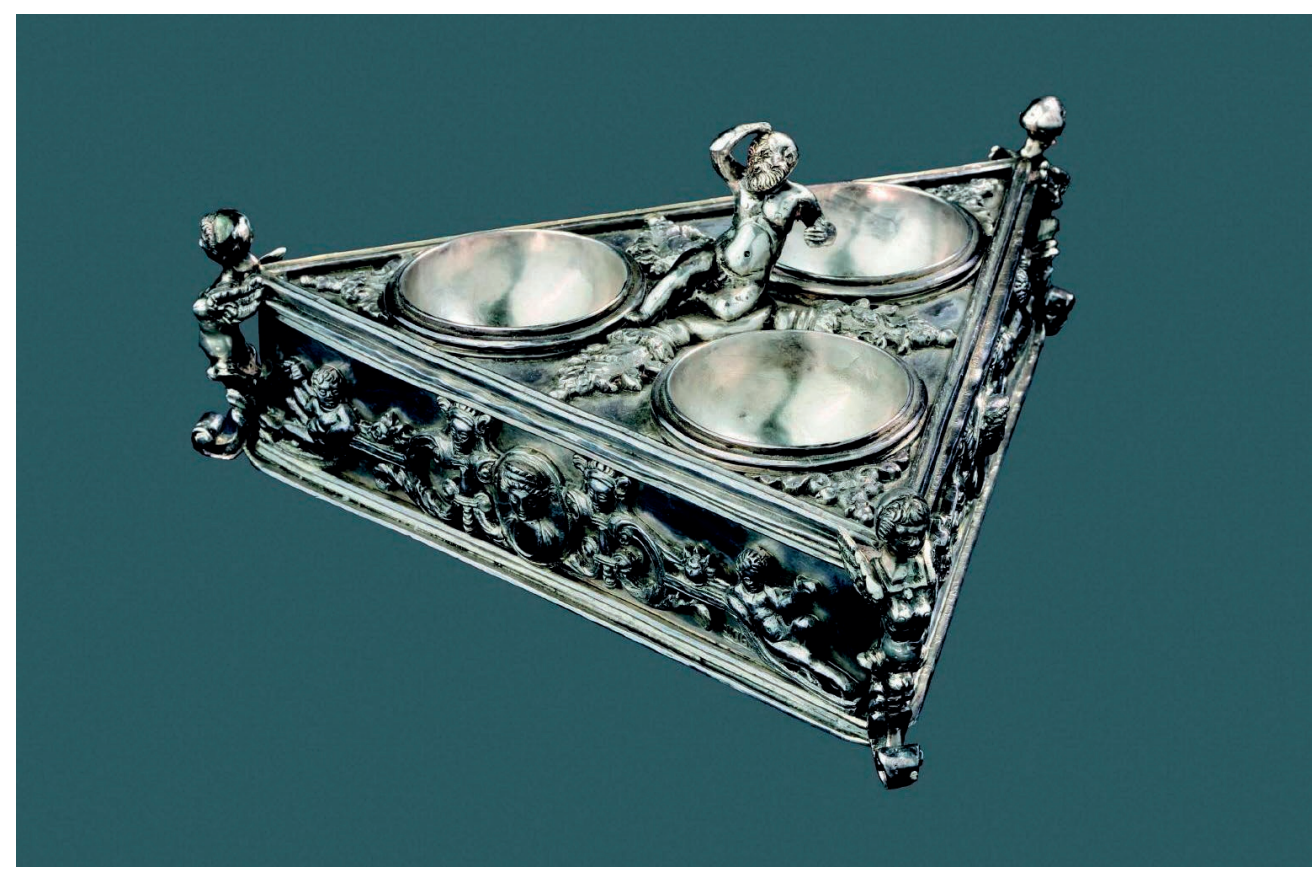

Figura 7. Especiero. Taller zaragozano, c. 1600.

Fuente: Museo Arqueológico Nacional, José Luis Municio Bacía.

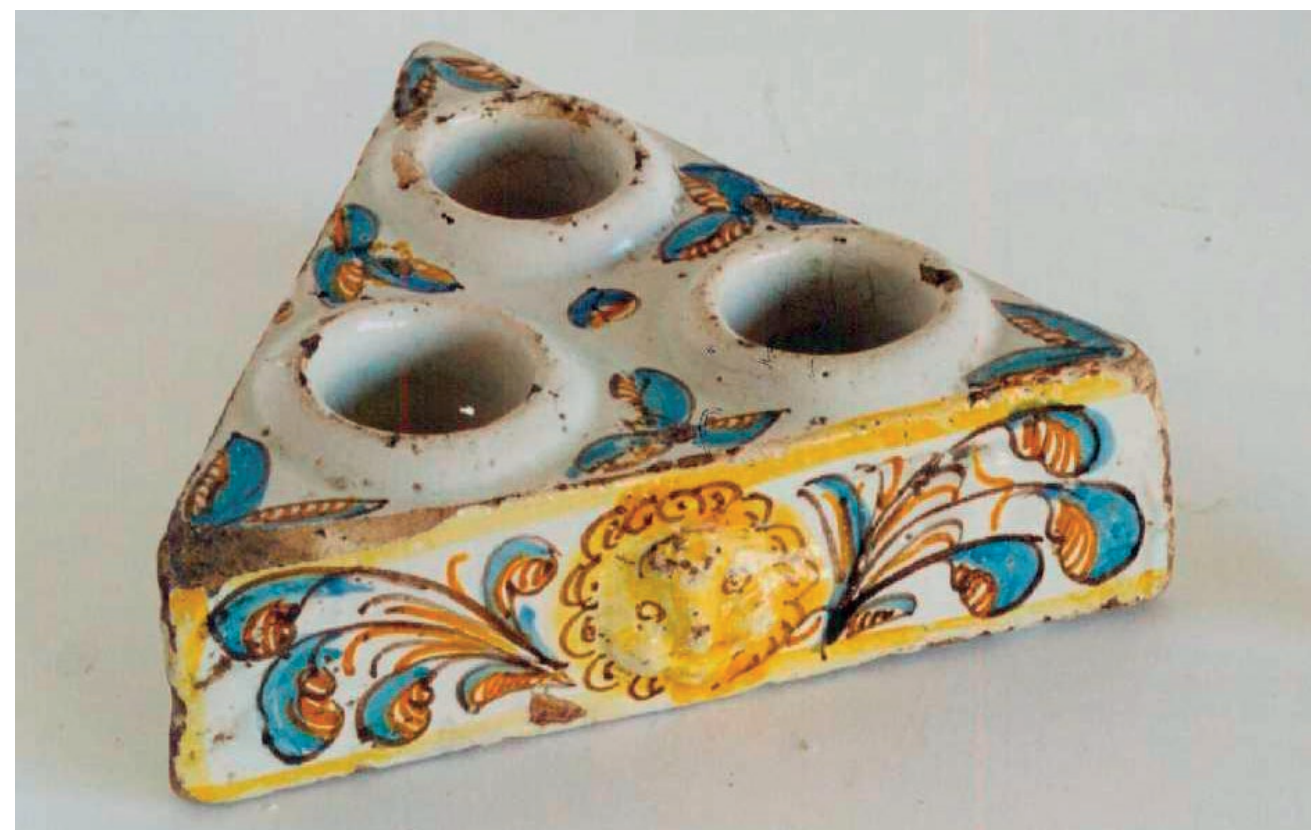

Figura 8. Especiero. Taller de Talavera de la Reina, segundo cuarto del siglo XVII. Fuente: Museo Nacional de Artes Decorativas. 
sal sobre la mesa era síntoma de mal agüero. De hecho, actualmente el diccionario de la Real Academia Española sigue recogiendo mendocino como sinónimo de supersticioso, aunque en desuso. Contamos con dos interesantes testimonios literarios que muestran la popularidad que llegó a tener esta creencia. El primero de ellos viene de la mano de Cervantes, quien aprovechó para hacer una crítica de las supersticiones en el Quijote:

Se le derrama a un Mendoza la sal encima de la mesa y se le derrama a él la melancolía por el corazón. ¡Como si la naturaleza estuviese obligada a dar señales de las desgracias venideras con cosas de tan poca importancia como las referidas! (Cervantes, 1605, t. VI, p. 165)

Recogemos en este mismo sentido otra cita de Quevedo en su Libro de todas las cosas y otras muchas más:

Si se te derrama el salero y no eres Mendoza, véngate del agüero y cómetele en los manjares. Y si lo eres, levántate sin comer y ayuna el agüero como si fuera santo, que por eso se cumple en ellos el agüero de la sal, porque siempre sucede desgracia, pues lo es no comer. (Quevedo, 1699, p. 461)

La documentación no aporta datos concretos acerca de la fecha en que se popularizó esta nueva tipología. En los inventarios la hemos hallado por primera vez en el año 1589 entre los bienes de Pedro de Herbas, camarero de la Seo de Zaragoza. ${ }^{13}$ Sin embargo, podemos aventurar que ya se comercializaba en la década de 1570 gracias a los exámenes de los plateros zaragozanos, barceloneses y valencianos. Aunque los dibujos de los primeros no se han conservado, las actas nos indican que los saleros fueron una de las piezas favoritas entre los aspirantes a maestros a partir de 1573 (San Vicente, 1976, t. II, pp. 38-270) y durante todo el siglo XVII (Esteban, 1981, t. I, pp. 95-149), habiéndose presentado en un total de veintitrés ocasiones. ${ }^{14}$ Los dibujos de los exámenes catalanes y levantinos, que sí podemos consultar total o parcialmente, muestran en las mismas fechas gran abundancia de saleros de torrecilla que debían ser similares a los producidos en Aragón (Cots, 2003, pp. 111, 369-374). ${ }^{15}$

Creemos que un vistazo a los dibujos de la Ciudad Condal nos permitirá acercarnos a las piezas aragonesas contemporáneas. Por ejemplo, en la documentación zaragozana hallamos un salero "con seys leoncicos por pies" (San Vicente, 1994, doc. 3) y otro "de dos piezas sobredorado con unos leones". ${ }^{16}$ El dibujo de maestría hecho por Francesc Vidal en 1595 nos muestra una pieza que debía ser ciertamente muy similar a las citadas, con garras y cabezas de león en el cuerpo inferior del salero (Figura 9).

Nuevamente, en el Instituto Valencia de don Juan se conservan dos saleros mendocinos o de torrecilla de ámbito aragonés, uno de dos cuerpos con punzón de Zaragoza perteneciente al segundo tercio del siglo XVI (Figura 10) y otro carente de punzón datado a finales de la misma centuria (Figura 11) (Montalvo, 2009, figuras. 1 y 3). Ambos cuentan con una decoración muy

\footnotetext{
${ }^{13}$ AHPNZ, Jerónimo Andrés, 1589, ff. 403 v.-430 v. (15-III-1589, Zaragoza).

${ }^{14}$ Añadimos a los exámenes conocidos con anterioridad los de Luis Lanzarote con "un salero de tres pieças de plata blanca quadrado", Miguel Cubels con un "salero de tres pieças quadrado" y Francisco Vinierta con "un salero quadrado de plata sobredorada de tres pieças con obalos". En AHPNZ, Diego Miguel Malo, 1600, ff. 259 v.-261 r. (6-V-1600, Zaragoza); AHPNZ, Diego Miguel Malo, 1602, ff. 52 v.-53 v. (10-I-1602, Zaragoza); y AHPNZ, Diego Miguel Malo, 1603-1604, ff. 361 v.-362 V. (29-VIII-1603, Zaragoza); respectivamente.

${ }^{15}$ El primero de los saleros dibujados en las pasentías barcelonesas es obra de Joan Gonsalvo y data de 1571. En Arxiu Històric de la Ciutat de Barcelona [AHCB], Llibre de Passenties, vol. II (18-IV-1571, Barcelona).

${ }^{16}$ Capitulaciones matrimoniales entre Antonio Fernández de Híjar, caballero de la orden de Calatrava, y Juana Sobrino, viuda de Juan de Marcilla. En AHPNZ, Juan Domingo Navarro, 1602, ff. 80 r.-125 v. (10-I-1602, Zaragoza).
} 


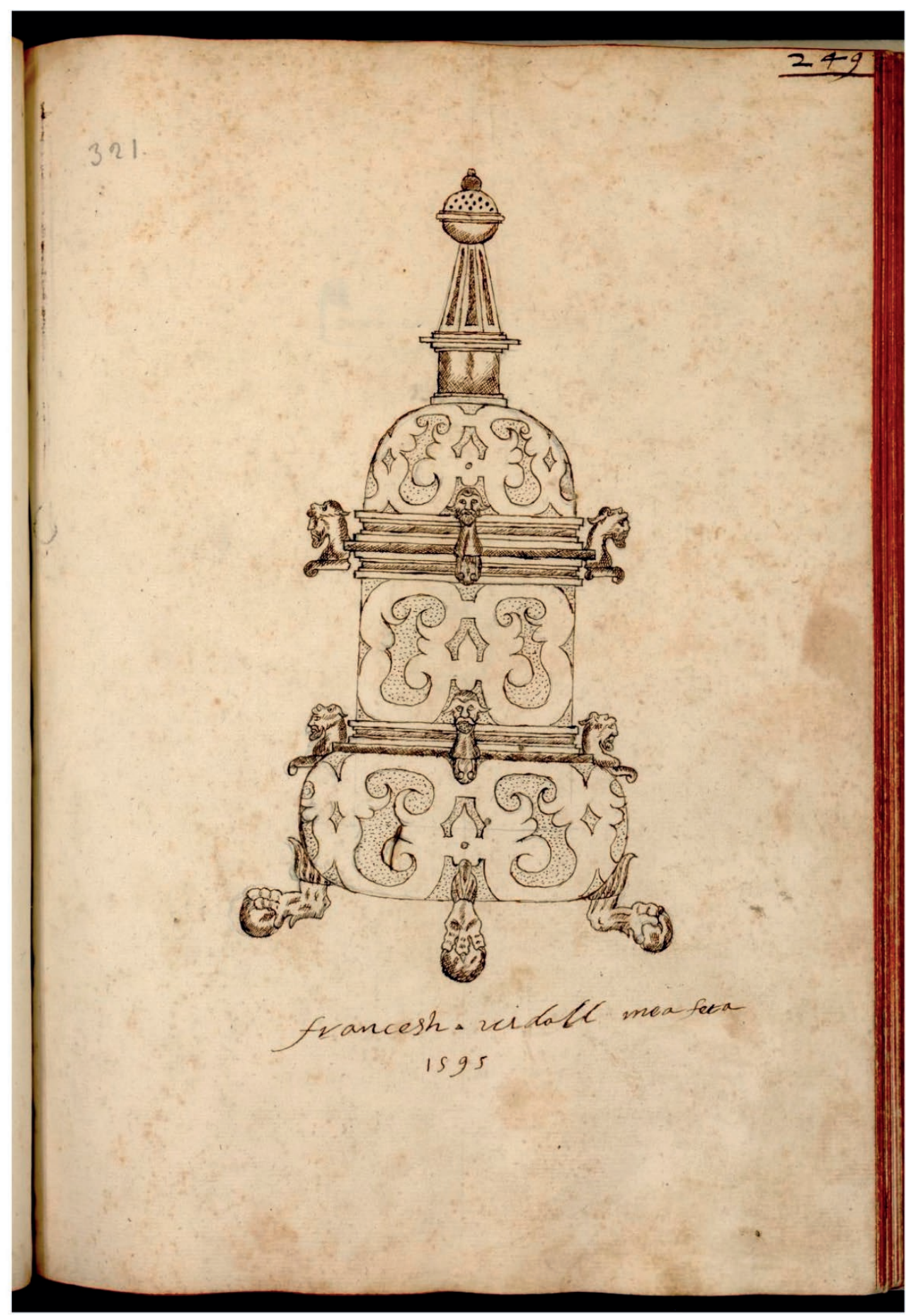

Figura 9. Dibujo de salero de torrecilla o mendocino. Francesc Vidal, 1595. Fuente: Arxiu Històric de la Ciutat de Barcelona. 


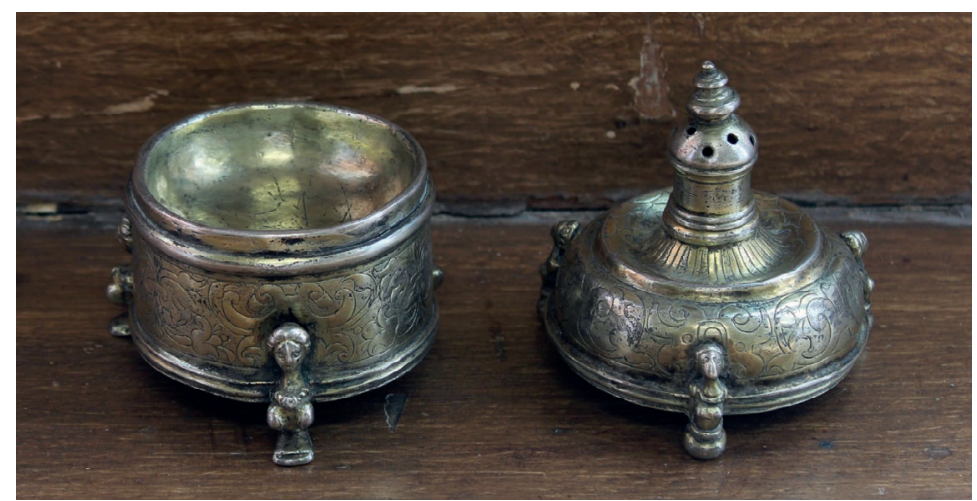

Figura 10. Salero del Instituto Valencia de Don Juan. Fuente: elaboración propia.

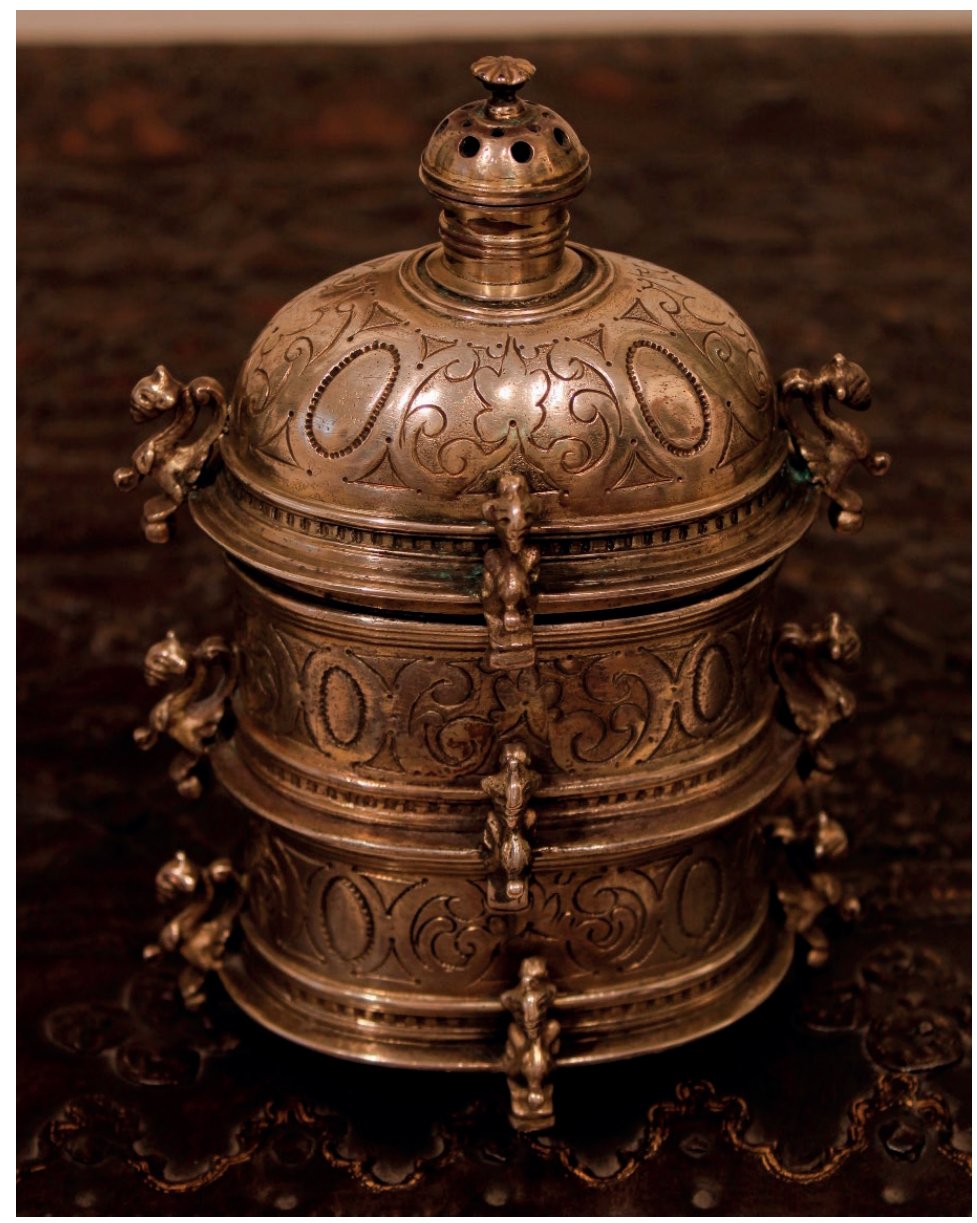

Figura 11. Salero del Instituto Valencia de Don Juan. Posible taller aragonés, finales del siglo XVI. Fuente: elaboración propia. 
sencilla de carácter vegetal, geométrico y con pies antropomorfos y zoomorfos. Si atendemos a la documentación, encontramos palabras y expresiones que describen otras decoraciones posibles como labrados a la morisca (Cardesa, 1993, p. 313, doc. 35), canalado (Lanaspa, 2005, p. 102, doc. 2235(2.500)), çicelado, de medio relieve (Longás, 2006, p. 203, doc. 7-9504(10328)) y sobredorados o de plata blanca, estas dos últimas opciones en relación con el tratamiento cromático de la pieza. Por último, citamos un curioso salero "ahobado con su cobertor que sirve de pimentero y encima del como por chapitel un niño con un escudo y en el un coraçon con una saeta atravesado y unos agujeros en que se ponen palillos para los dientes" (Lanaspa, 2005, p. 200, doc. 2-2783(3.190)), detallada descripción de un objeto de bella iconografía que pone de relieve la variedad de productos que se podían encontrar en el mercado.

\section{El salero en el contexto del banquete: mesas, aparadores y talleres}

Una vez definidas tipológicamente las diferentes formas que podían adquirir los saleros y especieros, vemos necesario exponer cómo se presentaban ante los comensales. En el Estilo de servir a príncipes de Yelgo de Bázquez encontramos la explicación más sencilla al respecto:

Puestos los manteles, lo primero se pondra el salero o saleros, y a un lado el pimentero, y a otro lado el açucarero, y luego empeçara a poner servicios, empeçando por la cabecera, baxando por el lado derecho de la mesa (Yelgo, 1614, p. 159).

Encontramos documentado en Teruel este tratado sobre el servicio de las casas nobles en fechas tan tempranas como 1626, en el inventario de los bienes de Lorenzo Gamir Palomar e Inés Guillén Pérez Cardona. ${ }^{17}$ Según sus indicaciones, el salero se colocaba en primer lugar en el centro de la mesa, acompañado de los respectivos receptáculos para la pimienta y el azúcar, hecho que también podemos confirmar a través de la representación pictórica.

Hemos escogido dos obras de autor aragonés con el mismo tema, la Última Cena, en las que los artistas aprovecharon para representar un banquete. ${ }^{18}$ En primer lugar, en el Museo Diocesano de Albarracín se conserva un lienzo atribuido al alcorisano Pedro García Ferrer (Almagro/Arce, 2011). Efectivamente, en el espacio central de la mesa y frente a Cristo se sitúa un salero dorado, mendocino y desmontado (Fig. 12). En la segunda pintura, ejecutada por Pedro Rabiella y Diez de Aux y custodiada en el Museo de Zaragoza, el salero guarda una disposición muy similar, junto al pan (Fig. 13). ${ }^{19}$

Colocarlos en el centro de la mesa no era la única posibilidad. Los saleros también encontraban su lugar en aparadores y reposteros junto a otros objetos de gran belleza estética y lujo que buscaban remarcar el poder del anfitrión. El Diccionario de Autoridades describe un aparador como "el conjunto de alhájas [...] que se ponen sobre una mesa con sus gradillas, assi para servirse de ellas quando sea necessário, como para que sirvan de adorno [...] en las mesas de los Príncipes" (Diccionario de Autoridades, 1726-1739). Por lo tanto, su inclusión en estos conjuntos

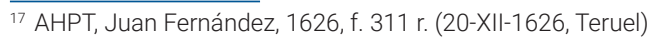

${ }^{18}$ Agradecemos a Álvaro Vicente Romeo su ayuda en la selección de estas dos pinturas.

${ }^{19}$ En este caso cabe destacar la similitud de la pieza representada con el dibujo que el platero Pedro Vespín, natural de Oliete (Teruel), realizó para acceder al gremio de plateros de Valencia en 1669. Se trata de un modelo carente de tapa y decoración, mucho más simple que el mendocino o de torrecilla, que se repite en la segunda mitad del siglo XVII e inicios del XVIII (Cots, 2003, pp. 371-372). También se encuentra producido en cerámica, como la pieza turolense con el número de inventario CE03435 del Museo Nacional de Artes Decorativas.
} 


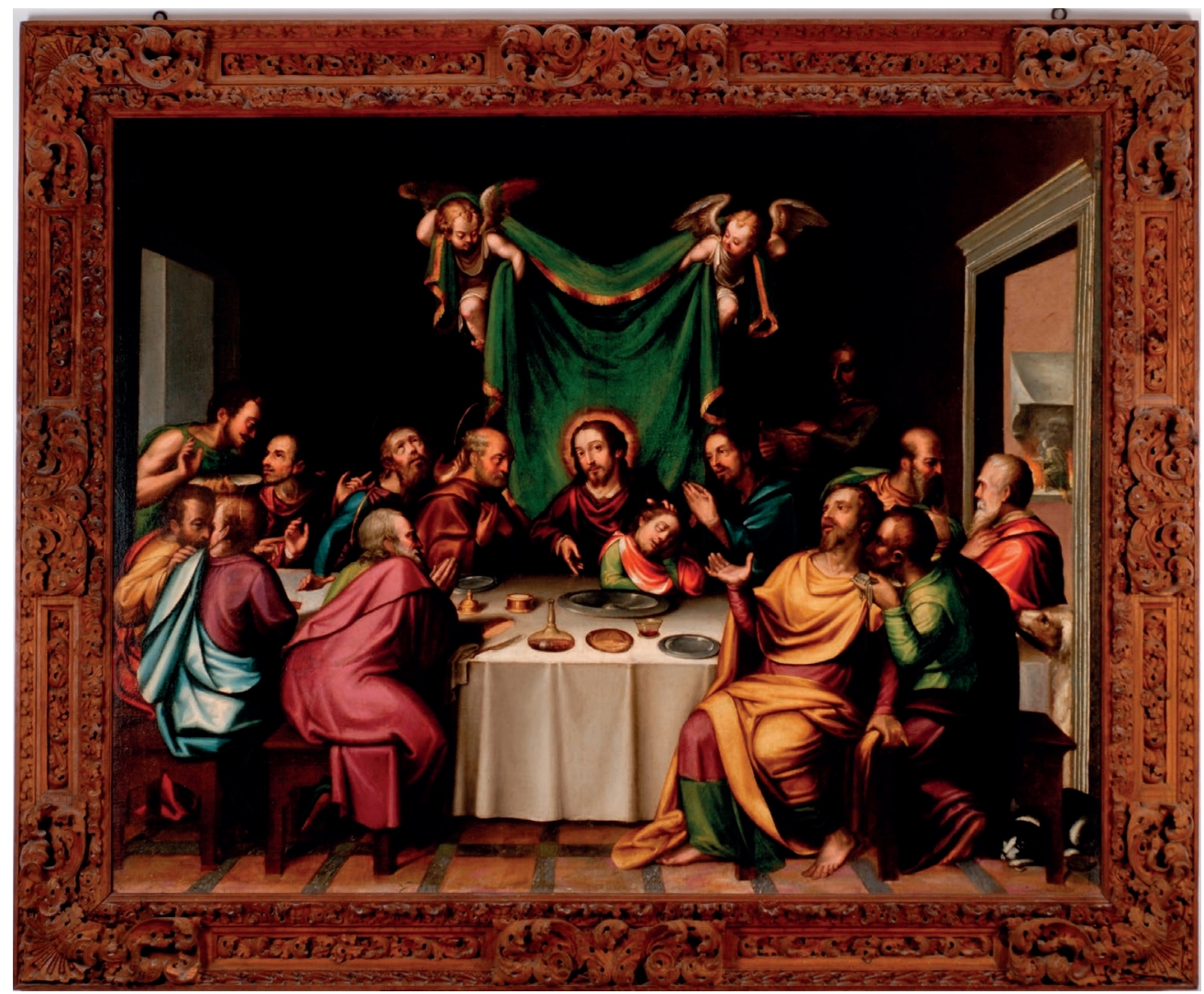

Figura 12. Última Cena [detalle]. Atrib. Pedro García Ferrer, primera mitad del siglo XVII. Fuente: Fundación Santa María de Albarracín.

nos da una nueva nota de que tanto las especias como sus contenedores eran elementos con una función no solo utilitaria, sino también simbólica y representativa de la capacidad económica del anfitrión. Acudimos por segunda vez a la pintura para poder ilustrar este fenómeno, en este caso a la Naturaleza muerta con objetos de orfebrería de Juan Bautista de Espinosa. El artista representó sobre el lienzo un conjunto de aparador formado por múltiples platos y bandejas de plata sobredorada, una copa bernegal, recipientes de diversos materiales, parte de la cubertería y, en primer plano, una pareja de salero y pimentero desmontados.

El componente social que tiene la exhibición de estos objetos y la consecuente demostración de poder económico explica que muchos de ellos puedan ir complementados con la heráldica de sus propietarios, como en el caso de la naveta conservada en la iglesia de San Pablo de Zaragoza. De esta manera, serían inmediatamente reconocidos como poseedores de tan exclusivos productos. En la documentación encontramos "una torreçilla en quatro piezas donde ay salero, azucarero, canelera y pimentera todo dorado con su caxa y armas del Vizconde" entre los bienes de Ana de Aragón, vizcondesa de Ébol, en 1595;20 y un salero "quadrado llano con

${ }^{20}$ AHPNZ, Diego Miguel Malo, 1595, ff. 226 r.-226 v. (30-III-1595, Zaragoza). 


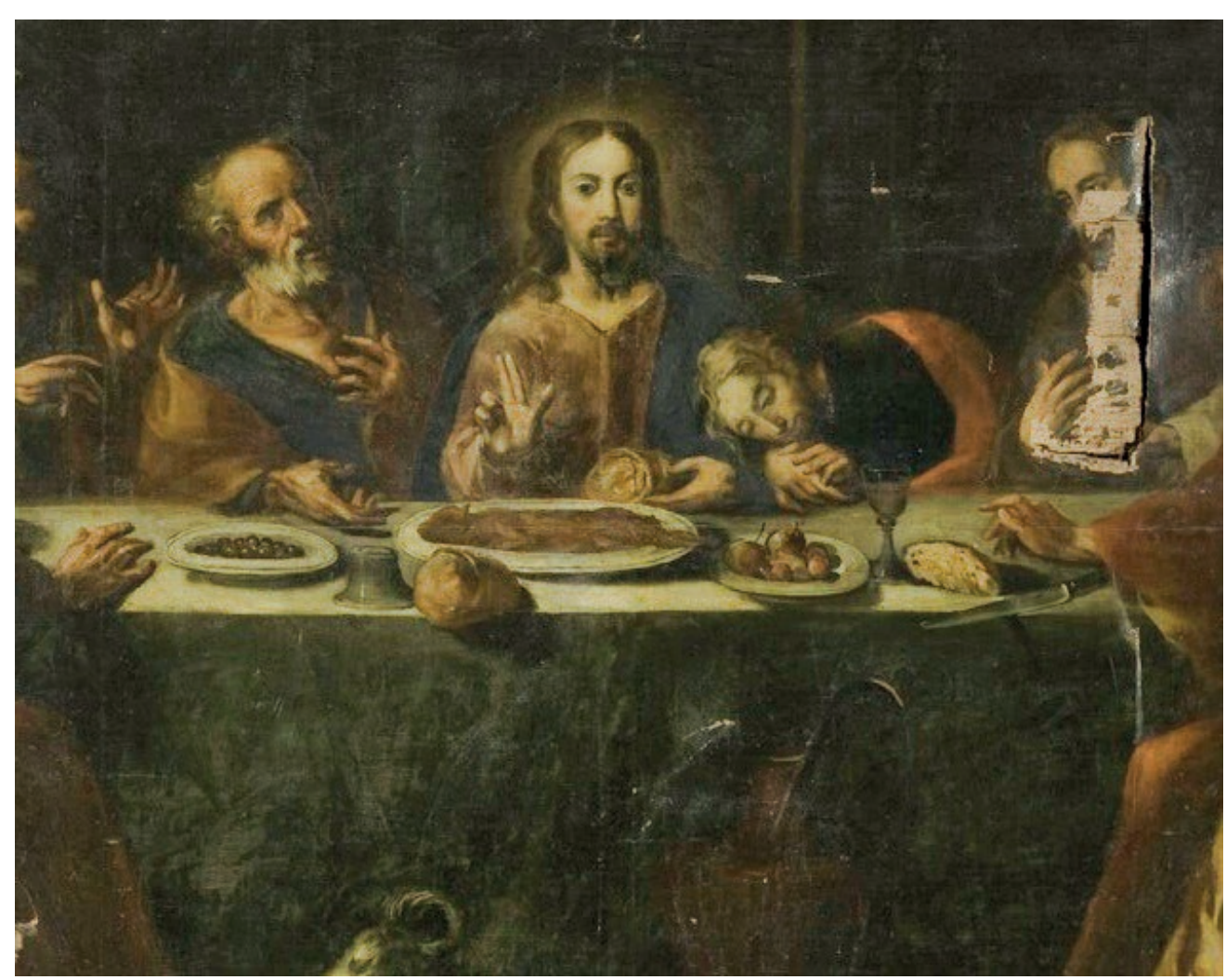

Figura 13. Última Cena [detalle]. Pedro Rabiella y Diez de Aux, 1704. Fuente: Museo de Zaragoza.

nuestras armas y unas bolas redondas en cada esquina que sirven de pies" de Antonio Ximénez de Urrea, conde de Aranda (Lanaspa, 2005, p. 200, doc. 2-2783(3.190)) en 1618.

Una tercera posibilidad eran los talleres, donde se situaban diversos recipientes para especias y aderezos. ${ }^{21}$ El Diccionario de Autoridades indica que un taller es "una pieza como una salvilla de plata, ù oro, que se pone en los aparadores de las mesas de los Señores: en medio un saléro, y à los quatro lados dos vasijas para azéite, y vinagre, y dos cubillos para pimienta, y azucar" (Diccionario de Autoridades, 1726-1739). Generalmente los talleres se restringen a las cinco piezas referidas en el diccionario, aunque en los documentos hemos encontrado algunos ejemplos extraordinarios.

El que cuenta con una descripción más completa perteneció a Francisca Luisa de Luna, marquesa de Camarasa. En su inventario post mortem realizado en 1585 se describe como "un plato dorado con pie y en el ay seis guecos y en medio ay un salero grande dorado con el cobertor de un toro de bulto. Ay en el plato una acucherera y una pementera y una torreçuela para canela y

${ }^{21}$ La palabra taller no se documenta en el ámbito hispánico hasta 1617, pero la tipología ya se utilizaba con anterioridad (Cruz, 1979, pp. 145-144). Hemos hallado dicho término en la documentación aragonesa por primera vez en 1618 en referencia a cinco talleres propiedad de Antonio Ximénez de Urrea, conde de Aranda (Lanaspa, 2005, p. 200, doc. 2-2783(3.190)). 
una azeytera y vinagera y otra de gengibre. Cada cofre destas tiene sus tapaderas y su letra y altas y todo ello dorado y todo el a pesado deziseis marcos", que se acompaña de nueve saleros adicionales. ${ }^{22}$ También podemos citar la "salva imperial de plata lisa con ocho pieças, con el joiello que sirve de remate al salero" que el arzobispo Tomás de Borja donó a su sobrino el duque de Lerma en 1608 (Abad, 2009, p. 358). Por último, los talleres también podían contar con elementos heráldicos, como "las armas de Yxar y Pinos" que ostentaba el de Francisca de Pinós y Fenollet, duquesa de Hijar y Condesa de Belchite (Longás, 2006, p. 203, doc. 7-9504(10328)). Por desgracia, no hemos hallado ningún taller, por completo o en estado fragmentario, de origen aragonés.

Finalmente, hemos documentado tres conjuntos de camino o de viaje en los que se repiten los parámetros domésticos, todos ellos pertenecientes a religiosos. Se trata de "una pila de plata redonda de camino dorada dentro en una capsa y una cuchara de plata dorada y una pimenterilla de plata" de Juan de Urrea, abad de Montearagón; ${ }^{23}$ "un baso de camino que ay en el dos tacas, dos candeleros, dos cucharas, dos orquillas, salero, pimentera y açucarera" de Juan de Paternoy, comendador de la orden de San Juan;24 y "un adreço de camino con un jarillo de plata, dos gobaletes, çucarera, salero y pimentera, tres cucharas y dos cuchillos dentro de su caxa" de Diego de Ramellori, canónigo de la Seo de Zaragoza (Jodrá, 2007, pp. 243-245, doc. 8-1016(1031)).

\section{Conclusión}

En las páginas anteriores hemos visto una gran cantidad de obras con formas, materiales y modos de uso diversos que parecen servir a un mismo objetivo muy simple: disponer la sal y las especias en la mesa. Esta acción puede parecer carente de interés a ojos del cocinero y del comensal contemporáneos por su precio asequible y fácil acceso. Sin embargo, en tiempos pasados su consecución era un acto restringido a una élite privilegiada. Las capas altas de la sociedad subordinaban todos los medios de producción con el objetivo de importar desde tierras lejanas unos condimentos que dotaban a sus manjares de un sabor, un color, un aroma y unas propiedades que les parecían extraordinarias.

La realeza, las familias nobles, la jerarquía eclesiástica y los comerciantes y ciudadanos más afortunados no restringían el uso de las especias a la cocina. Todos ellos querían disponer algunos de estos alimentos sobre la mesa para evidenciar sus posibilidades. Las fuentes documentales indican que la más popular era la pimienta, pero también el jengibre y la canela podían ofrecerse a los invitados junto a la sal y al azúcar. Por este motivo no se puede entender el papel de las especias desde una perspectiva únicamente gastronómica, sino también sociológica e incluso política. En un acto tan importante socialmente como el banquete, todos los sentidos formaban parte del despliegue de poder: el sabor de los platos, el aroma de las especias y otras sustancias fragantes y, por último, pero no menos importante, la belleza de la vajilla, de los objetos de arte y de los artilugios desplegados estratégicamente sobre la mesa para evocar los largos y costosos viajes que había sufragado el anfitrión, directa o indirectamente, para poder contentar a todos sus invitados.

\footnotetext{
${ }^{22}$ AHPNZ, Jerónimo Andrés, 1585, ff. 410 r.-536 r. (24-VI-1585, Zaragoza).

${ }^{23}$ AHPNZ, Pablo de Gurrea, 1547, ff. 37 v.-51 v. (12-I-1547, Zaragoza).

${ }^{24}$ AHPNZ, Juan Martín Sánchez de Castelar, 1604, ff. 1775 r.-1781 r. (1-XI-1604, Zaragoza).
} 
Finalmente, en este texto hemos incorporado una serie de objetos con la misma función primordial, pero menos exclusivos, realizados con técnicas cerámicas o con metales comunes, que utilizaba un grupo más amplio de la sociedad aragonesa para servir la sal sin la compañía de otras especias, al menos no con frecuencia. No obstante, los paralelismos formales entre las piezas de plata y las más modestas nos indican que había un cierto conocimiento de las prácticas gastronómicas de élite que se quisieron incorporar, ya sea por comodidad o por apariencia, en las mesas más humildes.

\section{Bibliografía}

ABAD ZARDOYA, C. (2005). La casa y los objetos. Espacio doméstico y cultura material en la Zaragoza de la primera mitad del XVIII. Zaragoza: Delegación del Gobierno en Aragón.

ABAD ZARDOYA, C. (2009). "Por el bien y beneficios que de su mano hemos recibido: estudio documental de una donación de bienes muebles hecha por Tomás de Borja a su sobrino el duque de Lerma en 1608". En: Artigrama, 24, pp. 341-371.

Almagro gORBEA, A. y ARCE OLIVA, E. (2011). El Palacio Episcopal de Albarracín. Albarracín: Fundación Santa María de Albarracín.

ALONSO BENITO, J. (2015). Platería. Colecciones del MNAD. Madrid: Ministerio de Educación, Cultura y Deporte.

ANDRÉS CASABÓN, J. y NAYA FRANCO, C. (2012). "Del deleite de los sentidos al ornato del culto divino: la naveta gótica del Museo de Tapices de La Seo de Zaragoza”. En: Artigrama, 27, pp. 375-393.

ARCE OLIVA, E. (2013). “La platería renacentista de la catedral de Albarracín: génesis de una colección”. En: Álvaro Zamora, M. I., Lomba Serrano, C., Pano Gracia, J. L. y Borrás Gualis, G. M. (coords.). Estudios de historia del arte: libro homenaje a Gonzalo M. Borrás Gualis. Zaragoza: Institución Fernando el Católico.

CASTILLÓN CORTADA, F. (2002). "Inventario litúrgico de la catedral de Roda de Isábena (Huesca)". En: Sobrarbe, 8, pp. 65-76.

CERVANTES SAAVEDRA, M. de (1605). El ingenioso hidalgo don Quijote de la Mancha, edición de 1839. Madrid: D. E. Aguado.

COTS MORATÓ, F. de P. (2003). El examen de maestría en el arte de plateros de Valencia (1595-1882). Valencia: Ajuntament de València.

CRUZ VALDOVINOS, J. M. (1979). "Plata de vajilla: talleres castellanos". En: Archivo Español de Arte, 206, pp. 145-168.

CRUZ VALDOVINOS, J. M. (1997). Platería europea en España (1300-1700). Madrid: Fundación Central Hispano.

CRUZ VALDOVINOS, J. M. (2014). "Piezas de platería aragonesa de Época Moderna en subastas internacionales recientes (2008-2011)". En: Ars Renovatio, 2, pp. 154-163.

DICCIONARIO de AUTORIDADES (1726). Diccionario de Autoridades - Tomo I (1726) - Aparador. <https://apps2.rae.es/DA.html< [Consulta: 29 de septiembre de 2021] 
EBERENZ, R. (2018). "Discurso y léxico de la alimentación en los tratados médicos medievales y renacentistas". En: Arnal Purroy, M. L., Castañer Martín, R. M., Enguita Utrilla, J. M., Lagüéns Gracia, V. y Martín Zorraquino, M. A. (coords.). Actas del X Congreso Internacional de Historia de la Lengua Española. Zaragoza: Institución Fernando el Católico, vol. II, pp. 1075-1088.

ESTEBAN LORENTE, J. F. (1981). La platería de Zaragoza en los siglos XVII y XVIII. Madrid: Ministerio de Cultura.

ESTERAS MARTÍN, C. (1975). "Inventario artístico de la orfebrería religiosa en la ciudad de Albarracín”. En: Teruel, 53, pp. 105-146.

ESTERAS MARTíN, C. (1980). Orfebrería de Teruel y su provincia. Teruel: Instituto de Estudios Turolenses.

GARRIDO ARANDA, A., HIDALGO NUCHERA, P. y RAMíREZ PONFERRADA, M. D. (2004). "Papel de hierbas aromáticas y especias en la alimentación española de los tiempos modernos". En: Garrido Aranda, A. (comp.). El sabor del sabor. Hierbas aromáticas, codimentos y especias. Córdoba: Servicio de publicaciones de la Universidad de Córdoba, pp. 121-152.

GIL ASENJO, M. I. (1984). Documentación artística en los años 1652, 1653 y 1654, según el Archivo Histórico Provincial de Zaragoza. Tesina. Zaragoza: Universidad de Zaragoza.

GÓMEZ DE VALENZUELA, M. (2017). Platería y joyería en Zaragoza (1412-1513). Zaragoza: Institución Fernando el Católico.

LANASPA MORENO, M. A. (2005). Las artes en Aragón en el siglo XVII según el Archivo de Protocolos notariales de Zaragoza, de 1616 a 1618. Zaragoza: Institución Fernando el Católico.

LATORRE GRACIA, N. (1984). Documentación artística en los años 1640, 1641 y 1642, según el Archivo Histórico Provincial de Zaragoza. Tesina. Zaragoza: Universidad de Zaragoza.

LONGÁS LACASA, M. Á. (2006). Las artes en Aragón en el siglo XVII según el Archivo de Protocolos notariales de Zaragoza, de 1631 a 1633. Zaragoza: Institución Fernando el Católico.

MALDONADO NIETO, M. T. y MONTUENDO BARREIDO, A. (1979). Plata espanyola des del segle XV al XIX. Barcelona: Sala d'Art Daedalus.

MAÑUECO SANTURTÚN, C. (2002). "Especiero”. En: Flórez Plaza, P. (coord.) y González Martínez, R. (coord.). Arte y Poesía. El amor y la guerra en el Renacimiento. Madrid: Ministerio de Educación, Cultura y Deporte, p. 437.

MARTíN DOMINGO, F. (2009). "Las salinas de Ojos Negros". En: Cuadernos del Baile de San Roque, 22, pp. 61-72.

MONTALVO MARTÍN, F. J. (2009). "Especieros de plata hispanos del Instituto Valencia de Don Juan”. En: Goya, 329, pp. 352-361.

PÉREZ SÁMPER, M. de los Á. (1997). “Los recetarios de mujeres y para mujeres. Sobre la conservación y transmisión de los saberes domésticos en la época moderna". En: Cuadernos de Historia Moderna, 19, pp. 121-154.

POSTIGO VIDAL, J. (2015). La vida fragmentada, experiencias y tensiones cotidianas en Zaragoza (siglos XVII y XVIII). Zaragoza: Institución Fernando el Catíólico. 
QUEVEDO, F. de (1699). Obras de Francisco de Quevedo Villegas. Amberes: Henrico y Cornelio Verdussen.

RIERA MELIS, A. (2004). "Las especias en el Mediterráneo noroccidental en la Antigüedad tardía y la Alta Edad Media”. En: Garrido Aranda, A. (comp.). El sabor del sabor. Hierbas aromáticas, codimentos y especias. Córdoba: Servicio de publicaciones de la Universidad de Córdoba, pp. 47-69.

SAN VICENTE PINO, Á (1976). La platería de Zaragoza en el bajo Renacimiento, 1545-1599. Zaragoza: Pórtico.

SAN VICENTE PINO, Á, (1994). "Diez documentos escogidos sobre precios de bienes y servicios en Zaragoza en el siglo XVI”. En: Lobo Cabrera, M. y Suárez Grimón, V. El comercio en el Antiguo Régimen, III reunión científica de la asociación española de historia moderna. Las Palmas de Gran Canaria: Universidad de Las Palmas de Gran Canaria, pp. 261-275.

SAN VICENTE PINO, Á. (1988). Instrumentos para una historia social y económica del trabajo en Zaragoza en los siglos XV a XVIII. Zaragoza: Real Sociedad Económica Aragonesa de Amigos del País.

SAN VICENTE PINO, Á. (1991). Lucidario de bellas artes en Zaragoza, 1545-1599. Zaragoza: Real Sociedad Económica Aragonesa de Amigos del País.

YELGO DE BÁZQUEZ, M. (1614). Estilo de servir a principes, con exemplos morales para servir a Dios. Madrid: Cosme Delgado. 